\title{
Effect of carbon monoxide on Mycobacterium tuberculosis pathogenesis
}

\author{
Vineetha M Zacharia ${ }^{1}$ and Michael U Shiloh ${ }^{2^{*}}$
}

\begin{abstract}
The intracellular pathogen Mycobacterium tuberculosis (Mtb) is exposed to multiple host antimicrobial pathways, including toxic gases such as superoxide, nitric oxide and carbon monoxide (CO). To survive, mycobacteria evolved mechanisms to resist the toxic environment, and in this review we focus on a relatively new field, namely, the role of macrophage heme oxygenase and its enzymatic product CO in Mtb pathogenesis. In particular, we focus on (i) the induction of heme oxygenase during Mtb infection and its relevance to Mtb pathogenesis, (ii) the ability of mycobacteria to catabolize $\mathrm{CO}$, (iii) the transcriptional reprogramming of $\mathrm{Mtb}$ by exposure to $\mathrm{CO}$, (iv) the general antimicrobial properties of $\mathrm{CO}$ and $(\mathrm{V})$ new genetic evidence characterizing the ability of Mtb to resist CO toxicity. Developing a complete molecular and genetic understanding of the pathogenesis of $\mathrm{Mtb}$ is essential to its eventual eradication.
\end{abstract}

Keywords: Carbon monoxide, Heme oxygenase, Microbiology, Immunology, Mycobacterium tuberculosis, Microbial pathogenesis

\section{Introduction}

The success of a pathogen during infection depends upon its abilities to respond to and overcome a battery of host defense mechanisms. In response to bacterial infection, host cells generate a variety of toxic compounds to mediate microbial killing such as excess hydrogen ion $(\mathrm{H}+)$, hydrogen peroxide $\left(\mathrm{H}_{2} \mathrm{O}_{2}\right)$, hypochlorous acid $(\mathrm{HOCl})$, nitric oxide $(\mathrm{NO})$, and carbon monoxide $(\mathrm{CO})$. To promote intracellular survival, some pathogens such as Mycobacterium tuberculosis (Mtb) evolved multiple pathways to evade these host defenses. For example, mycobacteria utilize superoxide dismutase [1] and catalase $[2,3]$ to convert the toxic reactive oxygen intermediates superoxide and $\mathrm{H}_{2} \mathrm{O}_{2}$ to water and oxygen, while they also employ multiple mechanisms to resist nitric oxide toxicity [4-8].

Understanding Mtb resistance mechanisms against host defenses is of paramount importance as it is an endemic and epidemic pathogen that latently infects approximately one-third of the world's population [9]. Upon Mtb infection, host immune pathways are

\footnotetext{
*Correspondence: Michael.shiloh@utsouthwestern.edu

${ }^{2}$ Department of Microbiology, Division of Infectious Diseases, University of

Texas Southwestern Medical Center, Dallas, TX 75229-9113, USA

Full list of author information is available at the end of the article
}

activated, resulting in macrophage and $\mathrm{T}$ cell recruitment [10]. The long-term success of Mtb as an intracellular pathogen lies primarily in its ability to remain dormant and persist within host macrophages for extended periods of time. This is facilitated in part by the induction of genes that comprise the dormancy regulon by stimuli present in the Mtb microenvironment including low oxygen, NO, nutrient starvation, and $\mathrm{CO}$ (Figure 1) [11-14]. The genes in the dormancy regulon, many which are of unknown function, likely contribute to $\mathrm{TB}$ persistence by facilitating its long-term survival [15].

Recent studies have described the deleterious effects of $\mathrm{CO}$ on various microbes, while unveiling the potential bacterial targets of $\mathrm{CO}$ action. In Escherichia coli, Pseudomonas aeruginosa, and Staphylococcus aureus, exposure to $\mathrm{CO}$ inhibits key enzymes of the electron transport chain required for bacterial respiration, resulting in microbial death $[16,17]$. In contrast to the aforementioned organisms, Mtb is able to withstand high concentrations of $\mathrm{CO}$, suggesting a potential $\mathrm{CO}$ resistance pathway not previously described in microorganisms [11]. In this review, we describe the role of the reactive gas compound $\mathrm{CO}$ and its relevance during

\section{Biomed Central}

(c) 2012 Zacharia and Shiloh; licensee BioMed Central Ltd. This is an Open Access article distributed under the terms of the Creative Commons Attribution License (http://creativecommons.org/licenses/by/2.0), which permits unrestricted use, distribution, and reproduction in any medium, provided the original work is properly cited. 


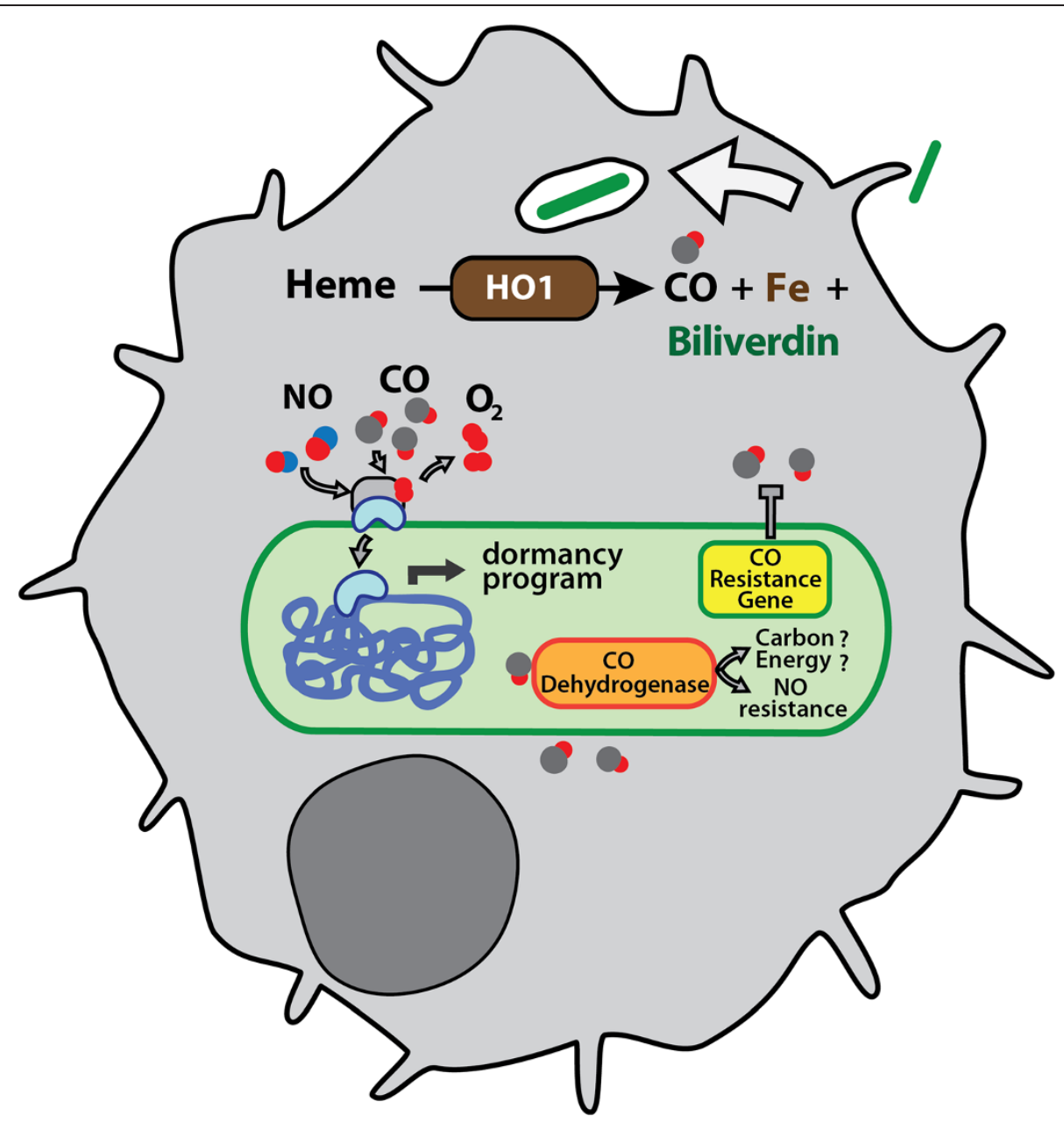

Figure 1 Role of carbon monoxide in M. tuberculosis pathogenesis. Macrophage infection by Mtb induces HO-1. HO-1 catabolizes heme to release $\mathrm{CO}$, iron and bilverdin. $\mathrm{CO}$ produced by $\mathrm{HO} 1$ can alter Mtb gene transcription by activating the DosS/DosR two component signal transduction system to stimulate a dormancy program. CO-mediated growth inhibition is resisted by the expression of a genetically encoded Mtb gene. Some mycobacteria can catabolize CO via CO dehydrogenase for growth. Alternatively, CODH may function in resisting host-derived nitric oxide.

microbial infection, while highlighting the ability of Mtb to withstand $\mathrm{CO}$ toxicity.

\section{Mtb infection increases heme oxygenase expression}

In humans and mice, three isoforms of heme oxygenase exist, HO-1, HO-2, HO-3 (encoded by Hmox1, Hmox2, and Hmox3 genes, respectively). All three isoforms catabolize heme, releasing as products free iron, biliverdin and $\mathrm{CO}$. $\mathrm{HO}-2$ and $\mathrm{HO}-3$ are constitutively expressed, whereas $\mathrm{HO}-1$ is induced by bacterial lipopolysaccharide, hypoxia, tumor necrosis factor (TNF), reactive nitrogen and oxygen intermediates $[18,19]$ and also by Mtb infection $[11,20]$. Upregulation of HO-1 may benefit host cells since $\mathrm{CO}$ and biliverdin/bilirubin can act as signaling molecules as well as provide cytoprotection. $\mathrm{CO}$ contributes to the cytoprotective effects of HO-1 by preventing free heme accumulation within cells, suppressing endothelial cell apoptosis, and modulating an anti-inflammatory response in macrophages upon exposure to bacterial lipopolysaccharide [21-23]. Likewise, both biliverdin and bilirubin (under the influence of biliverdin reductase) can protect cells from a variety of cytotoxic insults [24].

Notably, HO-1 deficient mice manifest decreased ability to overcome pathogenic infection and to recover from inflammatory diseases, xenotransplantation, and heart diseases (reviewed in [25]). In humans, a polymorphism in the Hmox 1 promoter result in differential expression of HO-1 such that individuals with fewer (GT)n repeats in the Hmox 1 promoter transcribe more $\mathrm{HO}-1$ in response to various stimuli, resulting in enhanced protection from both infectious and noninfectious diseases [26]. This strongly indicates that robust cellular HO-1 expression is crucial to overcome 
infectious and non-infectious diseases by mediating a wide range of host regulatory pathways.

Previously, we [11] and others [20] found that during Mtb infection, HO-1 is induced in both infected macrophages and mice suggesting that increased levels of $\mathrm{CO}$ might be present during Mtb infection (Figure 1) [11]. This induction occurred very early during mouse infection, i.e. within 10 days, and was concentrated in nascent granuloma and tissue macrophages [11]. The precise signaling mechanism of $\mathrm{HO}-1$ induction by $\mathrm{Mtb}$ is unknown, though bacterial factors, free heme, and inflammatory cytokines likely combine to induce $\mathrm{HO}-1$ transcription. Although the exact concentration of $\mathrm{CO}$ in lungs during Mtb infection is not known, CO concentrations can range from $2-50 \mathrm{ppm}$, depending on the physiologic status of the individual. Thus, the average, nonsmoking human exhales approximately $2 \mathrm{ppm}$ $[27,28]$ while patients with a variety of infectious and inflammatory conditions producing significantly more [27,29-32].

What might be the function of $\mathrm{HO}-1$ during infection? Considering that the induction is robust at the direct site of infection, i.e. macrophages within granuloma, it is feasible that HO-1 may be involved in controlling Mtb growth. Given the pleiotropic signaling activity of $\mathrm{HO}-1$ and $\mathrm{CO}$, other mechanisms might also be $\mathrm{HO}-1 / \mathrm{CO}$ dependent during Mtb infection. For example, HO-1 enhances interferon regulatory factor 3 (IRF3) phosphorylation and interferon- $\beta$ (IFN- $\beta$ ) production in Listeria or virally infected macrophages [33] and Mtb infection of macrophages rapidly induces IRF3 phosphorylation and IFN- $\beta$ production [34]. Thus, the observed activation of the IRF-3/IFN- $\beta$ pathway during Mtb infection [34] may also be HO-1 dependent. In addition to regulating cytokine production, $\mathrm{HO}-1$ and $\mathrm{CO}$ may also be involved in triggering the autophagy pathway for eradication of intracellular bacteria termed xenophagy [35]. Autophagy plays a major role in controlling Mtb infection infection $[36,37]$ and recent work found that inhibition of HO-1 prevented endotoxin-induced autophagy [38], suggesting that during Mtb infection, upregulation of $\mathrm{HO}-1$ with concomitant $\mathrm{CO}$ production enhances multiple innate immunity mechanisms.

\section{Carbon monoxide as a carbon and electron source in mycobacteria}

Albeit a toxic gas, carbon monoxide also functions as an intermediate molecule in bacterial metabolic pathways. Certain aerobic and anaerobic microorganisms, particularly those that utilize $\mathrm{CO}$ as the sole carbon and energy source (carboxydotrophs), employ the enzyme carbon monoxide dehydrogenase (CODH) to convert reactive carbon monoxide into more stable compounds [39].
Specifically, CODH catalyzes the reaction $\mathrm{CO}+\mathrm{H}_{2} \mathrm{O} \rightarrow$ $\mathrm{CO}_{2}+2 \mathrm{e}^{-}+2 \mathrm{H}^{+}$when organic carbon is absent (autotrophic growth) and carbon monoxide is present [40]. $\mathrm{CO}$ dehydrogenase is a complex metalloprotein composed of 3 polypeptides. In the carboxydotroph Oligotropha carboxydovorans, the three structural genes of $\mathrm{CODH}$ are coxL (for $\mathrm{CO}$ oxidation protein, Large subunit), $\operatorname{cox} M$ (medium subunit) and $\operatorname{coxS}$ (small subunit) (Figure 1). The entire cox cluster is transcriptionally induced when the bacteria are grown under autotrophic conditions in the presence of CO but not under heterotrophic conditions (organic carbon rich) [40]. Although the mechanism of this transcriptional induction remains unknown, these genes are necessary for autotrophic growth [41]. In aerobes, CODH coordinates molybdenum in its active site to oxidize $\mathrm{CO}$ to $\mathrm{CO}_{2}$ and the electrons generated from the oxidation reaction is transferred to the final electron acceptor such as ferredoxin, cytochromes, FMN or $\mathrm{FADH}_{2}$, which are then subsequently coupled to other energy requiring processes $[42,43]$. CODH in anaerobic microbes also catalyzes $\mathrm{CO}$ oxidation, but instead of coordinating molybdenum in its active site, it contains a $\mathrm{Ni}-\mathrm{Fe}$ active site. When coupled to acetyl-CoA synthase (ACS), CODH converts $\mathrm{CO}_{2}$ to $\mathrm{CO}$ in the Wood-Ljungdahl pathway for subsequent synthesis of a major carbon source, acetyl-CoA $[44,45]$. Thus, oxidation of CO can simultaneously produce energy for the cell and additional sources of carbon.

More recent evidence suggests that $\mathrm{CO}$ utilization via $\mathrm{CODH}$ is widespread among diverse microbial species, including the mycobacterial species $M$. bovis BCG, $M$. gordonae, M. smegmatis, and M. tuberculosis $[43,46,47]$. Mtb encodes for orthologues of CODH subunits [40]. The CODH structural genes are arranged in the transcriptional order 5' coxM (Rv0375c) -> coxS (Rv0374c) $\rightarrow \operatorname{coxL}$ (Rv0373c) 3', a genome structure shared by the majority of bacteria with cox homologues [40]. All three of the putative Mtb CODH proteins demonstrate high overall sequence similarity with $O$. carboxydovorans and all sequenced mycobacterial genomes including that of $M$. avium, $M$. bovis, $M$. leprae, and M. smegmatis encode for cox homologues with extremely high sequence similarity to Mtb [48]. Notably, as more genomes have been sequenced, cox homologues have been identified in several additional pulmonary pathogens, including Burkholderia sp., Rhodococcus sp., and Pseduomonas sp. (our unpublished observations).

The identification of cox homologues in various mycobacteria species prompted Park et al. to test the ability of mycobacteria to grow in vitro on $\mathrm{CO}$ as the sole carbon source [48]. Strikingly, all of the mycobacteria tested were able to grow on $\mathrm{CO}$ at $30 \%$ atmosphere as the sole carbon source, albeit more slowly [48]. Growth on CO required a long lag period after the bacteria were first 
subjected to CO-growth media, suggesting transcriptional induction of $\mathrm{CO}$ utilization genes [48]. Notably, CO-dependent growth of virulent Mtb was not tested. Additionally, Mtb and some of its relatives were found to utilize $\mathrm{CO}$ at $<1-5$ parts per million (ppm), an environmentally and physiologically relevant range since $\mathrm{CO}$ in the atmosphere and lungs measure at approximately 0.1 to $0.5 \mathrm{ppm}$ and $<3 \mathrm{ppm}$, respectively $[27,47]$. To date, no mutants in the cox genes have been reported in Mtb. However, that Mtb has retained these large genes during its evolution as a pathogen without a known ex vivo existence suggest that $\mathrm{Mtb}$ might utilize $\mathrm{CO}$ as an alternative carbon source, which may confer a selective advantage for Mtb within the nutrient-limited confines of a macrophage. An alternative explanation may be that the cox genes serve another function, namely, nitric oxide detoxification [49]. Although recombinant $\mathrm{CODH}$ from mycobacteria was able to oxidize $\mathrm{NO}$ and protect E. coli from NO mediated toxicity [49], direct genetic evidence that the cox genes are required by Mtb in vitro or in vivo to protect Mtb is lacking. Thus, mycobacterial CODH may have at least two activities, namely, $\mathrm{CO}$ uptake and $\mathrm{NO}$ detoxification, and further pathogenesis assays will be needed to dissect the precise function(s) of Mtb CODH (Figure 1).

\section{Gene expression of Mtb in the presence of carbon monoxide}

Since Mtb resides within the lung, and since $\mathrm{CO}$ is exhaled continuously, it is reasonable to predict that Mtb might have evolved mechanisms to detect and respond to changing $\mathrm{CO}$ fluxes, partly to sense the host immune status. In fact, both prokaryotes and eukaryotes have developed systems for sensing carbon monoxide [29,50-52]. For example, in eukaryotes the transcription factor NPAS2, implicated in regulating circadian rhythm, was shown to bind $\mathrm{CO}$ resulting in decreased DNA binding activity [53]. Likewise, the bacterium Rhodospirillum rubrum expresses a CO-binding transcription factor, CooA, whose function is to stimulate production of a $\mathrm{CO}$ oxidation system distinct from the one found in $O$. carboxydovorans [54-57]. How do organisms sense and measure CO? Commonly, these proteins contain an associated heme moiety which is not surprising given the propensity of $\mathrm{CO}$ to bind heme [50]. However, the physiologic conditions and precise mechanisms used by these proteins to bind both heme and $\mathrm{CO}$ are diverse. For instance, CooA from $R$. rubrum can only bind $\mathrm{CO}$ when its heme is in the ferrous $\left(\mathrm{Fe}^{2+}\right)$ state, a reduced condition found stably only under purely anaerobic conditions [57-59]. Thus, an organism like Mtb, which expresses a $\mathrm{CO}$ oxidation system under aerobic conditions [48] would be unlikely to express a CooA homologue, and in fact no CooA homologue can be identified in the Mtb genome.

To test the response of Mtb to CO, we exposed Mtb to $\mathrm{CO}$ in vitro and assessed the effects using transcriptional profiling [11]. We found that $\mathrm{CO}$ induces the transcription of a cohort of genes known as the dormancy (dos) regulon [11]. This induction occurred at $\mathrm{CO}$ concentrations as low as $20 \mathrm{ppm}$ headspace CO, but was most robust at concentrations above $2000 \mathrm{ppm}$ [11]. Mtb lacking the DosS/DosT two component system was unresponsive to $\mathrm{CO}$, indicating that DosS is the primary sensor for CO. Notably, DosS also sense NO and hypoxia via its heme binding domain (Figure 1) [60]. To confirm $\mathrm{CO}$ sensing can occur in vivo, we infected wildtype mouse macrophages and macrophages deficient in HO- 1 and found a significant abrogation of dormancy gene induction in the absence of HO-1 [11]. Similar results were obtained by Kumar et. al, confirming that Mtb can sense CO in vitro and in vivo [20].

\section{General antimicrobial properties of carbon monoxide}

It has been nearly four decades since preliminary studies have described the antibacterial effects of carbon monoxide. Specifically, CO was found to inhibit DNA replication in $E$. coli and it was postulated that $\mathrm{CO}$ may disrupt unwinding of the DNA duplex during replication, rather than directly inhibiting DNA polymerase activity [61]. However, it was later discovered that $\mathrm{CO}$ halts DNA replication by reducing the intracellular concentration of ATP and dNTPs. By disrupting enzymes in the electron transport and ATP production pathways, it was found that the presence of $\mathrm{CO}$ led to the depletion of deoxynucleoside triphospate pools in E. coli [62]. CO was also found to inhibit growth of the airborne bacteria Serratia marcescens by causing a flux in energy-generating pathways, namely the electron transport system [63].

Recently there has been revived interest in examining the role of exogenous $\mathrm{CO}$ on bacterial growth using lipid-soluble carbon monoxide-releasing molecules (CORMs). The original CORMs were metal carbonyl compounds that release $\mathrm{CO}$ at physiologically relevant concentrations in biological systems [64]. More recently, newer CORMs have been synthesized that represent unique chemistry [65] and multiple CORM compounds are effective antimicrobial molecules against both gram negative and gram-positive bacteria. In a recent study by Nobre et al., cultures of E. coli and S. aureus were treated with CORM-2 and CORM-3 under aerobic and anaerobic conditions to determine cell viability [66]. In the presence of either CORM, the strains suffered the toxic effects of $\mathrm{CO}$ as marked by a significant reduction of $\mathrm{CFU} / \mathrm{mL}$ compared to cells not treated with a CORM. Furthermore, the study reveals that the bactericidal 
effects of $\mathrm{CO}$ were observed under both aerobic and anaerobic conditions, indicating that there are additional bacterial targets for $\mathrm{CO}$ aside from the components involved in aerobic respiration [66]. The potency of CORMs as antimicrobial compounds is further underscored by a study that described reduced cell viability of laboratory and antibiotic-resistant strains of $P$. aeruginosa when treated with CORM3 [16]. ALF-62, a different class of CO-RM containing molybdenum, and CORM2 were recently tested on E. coli to elucidate the mechanism by which $\mathrm{CO}$ inhibited bacterial growth [65]. In their study, Tavares et al. report an accumulation of endogenous reactive oxygen species (ROS) in the presence of these CORMs and observe rescued growth of CORM treated E. coli when supplemented with various antioxidants [65].

\section{In vitro survival of mycobacteria in the presence of $\mathrm{CO}$ and identification of $\mathrm{CO}$ resistance gene in Mtb}

Although CO toxicity is widespread among diverse bacterial species, Mtb can withstand elevated CO concentrations with only minimal growth inhibition [11]. Under aerobic conditions, when Mtb are treated with $\mathrm{CO}$ during log phase, the bacteria are able to effectively resist CO-mediated growth inhibition [11]. Considering that Mtb senses CO in vitro via the DosS/DosT twocomponent system and its growth in vitro is not severely diminished in the presence of $\mathrm{CO}$ (unlike other bacteria when treated with $\mathrm{CO}$ ), we hypothesized that $\mathrm{Mtb} \mathrm{CO}$ resistance is genetically encoded. To identify such a gene, we generated an Mtb transposon mutant library and screened for mutants that did not grow in the presence of $\mathrm{CO}$ when compared to its growth in the presence of air (Zacharia, et. al, submitted). Interestingly, we identified such a mutant and mapped the transposon insertion to a gene region conserved in mycobacterial species and even phylogenetically distinct organisms such as Thermatoga maritima and Rhodococcus fascians. To confirm that the newly identified gene does indeed confer CO resistance, Zacharia et al. complemented the mutant with the cloned gene of interest, and observed a rescued growth phenotype in the presence of $\mathrm{CO}$ (Zacharia, et. al, submitted). Importantly, the mutant's ability to survive inside wild type macrophages was considerably less than that of wild type Mtb. Moreover, the mutant Mtb strain is attenuated for virulence in a mouse aerosol model of Mtb infection. Thus, host-derived CO can limit Mtb growth in macrophages and mice (Zacharia, et. al, submitted). This discovery of a novel protein involved in $\mathrm{CO}$ resistance marks the initial identification of a $\mathrm{CO}$ resistance gene in a pathogen. Multiple lines of experimentation are being actively pursued (biochemical, genetic, bioinformatics) to characterize the molecular function of this mycobacterial $\mathrm{CO}$ resistance protein to ultimately determine its role in contributing to Mtb pathogenesis.

\section{Concluding remarks}

The effects of $\mathrm{CO}$ on bacterial and mammalian cells are diverse including acting as a signaling molecule involved in regulating gene expression [52,53] to serving as a potent, toxic gas capable of inhibiting bacterial growth (Zacharia, et. al, submitted). Amongst human pathogens, Mycobacterium tuberculosis is currently the only one known to change its gene expression in response to varying $\mathrm{CO}$ concentrations. Some mycobacteria can use $\mathrm{CO}$ as a source of energy, but whether Mtb does so during infection remains unknown. However, when host macrophages produce $\mathrm{CO}$ Mtb responds by expressing its own CO resistance genes. The ability of Mtb to survive in the presence of $\mathrm{CO}$, in contrast to other known pathogens, indicates that Mtb has uniquely evolved mechanisms to bypass $\mathrm{CO}$ toxicity. The identification and characterization of a $\mathrm{CO}$ resistance gene and its associated pathways will provide a more comprehensive understanding of Mtb pathogenesis and on a broader scale, host-pathogen interactions.

\section{Abbreviations}

ATP: Adenosine triphosphate; CO: Carbon monoxide; $\mathrm{CODH}$ : Carbon monoxide dehydrogenase; CORM: Carbon monoxide releasing molecule; DNA: Deoxyribonucleic acid; dNTP: Deoxyribonucleotide; $\mathrm{H}_{2} \mathrm{O}_{2}$ : Hydrogen peroxide; HO: Heme oxygenase; IFN- $\beta$ : Interferon beta; IRF3: Interferon regulatory factor 3; Mtb: Mycobacterium tuberculosis; NO: Nitric oxide; TNF: Tumor necrosis factor

\section{Competing interests}

The authors declare no competing interests.

\section{Authors' contributions}

Both VMZ and MUS conceived of and drafted the manuscript. Both authors read and approved the final manuscript.

\section{Acknowledgements}

Work by the authors was funded by the Disease Oriented Clinical Scholar's program at UT Southwestern and NIH R01 AI099439 (M.U.S.) and by NIH T32 training grant 5T32Al007520 (V.M.Z.).

\section{Author details}

'Department of Medicine, Division of Infectious Diseases, University of Texas Southwestern Medical Center, Dallas, TX 75229-9113, USA. ²Department of Microbiology, Division of Infectious Diseases, University of Texas Southwestern Medical Center, Dallas, TX 75229-9113, USA

Received: 24 September 2012 Accepted: 4 December 2012 Published: 17 December 2012

\section{References}

1. Edwards KM, Cynamon MH, Voladri RK, Hager CC, DeStefano MS, Tham KT, Lakey DL, Bochan MR, Kernodle DS: Iron-cofactored superoxide dismutase inhibits host responses to Mycobacterium tuberculosis. Am J Respir Crit Care Med 2001, 164:2213-2219.

2. Li Z, Kelley C, Collins F, Rouse D, Morris S: Expression of katG in Mycobacterium tuberculosis is associated with its growth and persistence in mice and guinea pigs. J Infect Dis 1998, 177:1030-1035.

3. $\mathrm{Ng} \mathrm{VH,} \mathrm{Cox} \mathrm{JS,} \mathrm{Sousa} \mathrm{AO,} \mathrm{MacMicking} \mathrm{JD,} \mathrm{McKinney} \mathrm{JD:} \mathrm{Role} \mathrm{of} \mathrm{KatG}$ catalase-peroxidase in mycobacterial pathogenesis: countering the phagocyte oxidative burst. Mol Microbiol 2004, 52:1291-1302. 
4. Poole RK, Hughes MN: New functions for the ancient globin family: bacterial responses to nitric oxide and nitrosative stress. Mol Microbiol 2000, 36:775-783.

5. Darwin KH, Ehrt S, Gutierrez-Ramos JC, Weich N, Nathan CF: The proteasome of Mycobacterium tuberculosis is required for resistance to nitric oxide. Science 2003, 302:1963-1966.

6. Darwin $\mathrm{KH}$, Nathan CF: Role for nucleotide excision repair in virulence of Mycobacterium tuberculosis. Infect Immun 2005, 73:4581-4587.

7. Shi S, Ehrt S: Dihydrolipoamide acyltransferase is critical for Mycobacterium tuberculosis pathogenesis. Infect Immun 2006, 74:56-63.

8. Venugopal A, Bryk R, Shi S, Rhee K, Rath P, Schnappinger D, Ehrt S, Nathan C: Virulence of Mycobacterium tuberculosis depends on lipoamide dehydrogenase, a member of three multienzyme complexes. Cell Host Microbe 2011, 9:21-31.

9. Dye C, Scheele S, Dolin P, Pathania V, Raviglione MC: Consensus statement. Global burden of tuberculosis: estimated incidence, prevalence, and mortality by country. WHO Global Surveillance and Monitoring Project. AMA: the journal of the American Medical Association 1999, 282:677-686.

10. Parrish NM, Dick JD, Bishai WR: Mechanisms of latency in Mycobacterium tuberculosis. Trends Microbiol 1998, 6:107-112

11. Shiloh MU, Manzanillo P, Cox JS: Mycobacterium tuberculosis senses host-derived carbon monoxide during macrophage infection. Cell Host Microbe 2008, 3:323-330.

12. Voskuil MI, Visconti KC, Schoolnik GK: Mycobacterium tuberculosis gene expression during adaptation to stationary phase and low-oxygen dormancy. Tuberculosis (Edinb) 2004, 84:218-227.

13. Voskuil MI, Schnappinger D, Visconti KC, Harrell MI, Dolganov GM, Sherman DR, Schoolnik GK: Inhibition of respiration by nitric oxide induces a Mycobacterium tuberculosis dormancy program. J Exp Med 2003, 198:705-713.

14. Betts JC, Lukey PT, Robb LC, McAdam RA, Duncan K: Evaluation of a nutrient starvation model of Mycobacterium tuberculosis persistence by gene and protein expression profiling. Mol Microbiol 2002, 43:717-731.

15. Boon C, Dick T: How Mycobacterium tuberculosis goes to sleep: the dormancy survival regulator DosR a decade later. Future Microbiol 2012, 7:513-518.

16. Desmard M, Davidge KS, Bouvet O, Morin D, Roux D, Foresti R, Ricard JD, Denamur E, Poole RK, Montravers P, et al: A carbon monoxide-releasing molecule (CORM-3) exerts bactericidal activity against Pseudomonas aeruginosa and improves survival in an animal model of bacteraemia. FASEB journal: official publication of the Federation of American Societies for Experimental Biology 2009, 23:1023-1031.

17. Nobre LS, Al-Shahrour F, Dopazo J, Saraiva LM: Exploring the antimicrobial action of a carbon monoxide-releasing compound through wholegenome transcription profiling of Escherichia coli. Microbiology 2009, 155:813-824.

18. Slebos DJ, Ryter SW, Choi AM: Heme oxygenase-1 and carbon monoxide in pulmonary medicine. Respir Res 2003, 4:7

19. Donnelly LE, Barnes PJ: Expression of heme oxygenase in human airway epithelial cells. Am J Respir Cell Mol Biol 2001, 24:295-303.

20. Kumar A, Deshane JS, Crossman DK, Bolisetty S, Yan BS, Kramnik I, Agarwal A, Steyn AJ: Heme oxygenase-1-derived carbon monoxide induces the Mycobacterium tuberculosis dormancy regulon. J Biol Chem 2008, 283:18032-18039.

21. Pamplona A, Ferreira A, Balla J, Jeney V, Balla G, Epiphanio S, Chora A, Rodrigues CD, Gregoire IP, Cunha-Rodrigues M, et al: Heme oxygenase-1 and carbon monoxide suppress the pathogenesis of experimental cerebral malaria. Nat Med 2007, 13:703-710.

22. Otterbein LE, Bach FH, Alam J, Soares M, Tao Lu H, Wysk M, Davis RJ, Flavell RA, Choi AM: Carbon monoxide has anti-inflammatory effects involving the mitogen-activated protein kinase pathway. Nat Med 2000, 6:422-428

23. Brouard S, Otterbein LE, Anrather J, Tobiasch E, Bach FH, Choi AM, Soares MP: Carbon monoxide generated by heme oxygenase 1 suppresses endothelial cell apoptosis. J Exp Med 2000, 192:1015-1026.

24. Wegiel B, Otterbein LE: Go green: the anti-inflammatory effects of biliverdin reductase. Front Pharmacol 2012, 3:47.

25. Soares MP, Bach FH: Heme oxygenase-1: from biology to therapeutic potential. Trends Mol Med 2009, 15:50-58.

26. Yamaya M, Nakayama K, Ebihara S, Hirai H, Higuchi S, Sasaki H: Relationship between microsatellite polymorphism in the haem oxygenase-1 gene promoter and longevity of the normal Japanese population. J Med Genet 2003, 40:146-148.

27. Biernacki WA, Kharitonov SA, Barnes PJ: Exhaled carbon monoxide in patients with lower respiratory tract infection. Respir Med 2001, 95:1003-1005

28. Paredi $\mathrm{P}$, Shah $\mathrm{PL}$, Montuschi $\mathrm{P}$, Sullivan $\mathrm{P}$, Hodson ME, Kharitonov SA, Barnes PJ: Increased carbon monoxide in exhaled air of patients with cystic fibrosis. Thorax 1999, 54:917-920.

29. Ryter SW, Morse D, Choi AM: Carbon monoxide: to boldly go where NO has gone before. Sci STKE 2004, 2004:RE6.

30. Uasuf CG, Jatakanon A, James A, Kharitonov SA, Wilson NM, Barnes PJ: Exhaled carbon monoxide in childhood asthma. J Pediatr 1999, 135:569-574.

31. Antuni JD, Kharitonov SA, Hughes D, Hodson ME, Barnes PJ: Increase in exhaled carbon monoxide during exacerbations of cystic fibrosis. Thorax 2000, 55:138-142

32. Paredi P, Kharitonov SA, Barnes PJ: Exhaled carbon monoxide in lung disease. Eur Respir J 2003, 21(197):author reply 197-198.

33. Tzima S, Victoratos P, Kranidioti K, Alexiou M, Kollias G: Myeloid heme oxygenase- 1 regulates innate immunity and autoimmunity by modulating IFN-beta production. J Exp Med 2009, 206:1167-1179.

34. Manzanillo P, Shiloh MU, Portnoy DA, Cox JS: Mycobacterium Tuberculosis Activates the DNA-Dependent Cytosolic Surveillance Pathway within Macrophages. Cell Host Microbe 2012, 11:469-480.

35. Levine B, Mizushima N, Virgin HW: Autophagy in immunity and inflammation. Nature 2011, 469:323-335.

36. Gutierrez MG, Master SS, Singh SB, Taylor GA, Colombo Ml, Deretic V: Autophagy is a defense mechanism inhibiting BCG and Mycobacterium tuberculosis survival in infected macrophages. Cell 2004, 119:753-766.

37. Watson RO, Manzanillo PS, Cox JS: Extracellular M. tuberculosis DNA Targets Bacteria for Autophagy by Activating the Host DNA-Sensing Pathway. Cell 2012, 150:803-815.

38. Waltz P, Carchman EH, Young AC, Rao J, Rosengart MR, Kaczorowski D, Zuckerbraun BS: Lipopolysaccaride induces autophagic signaling in macrophages via a TLR4, heme oxygenase-1 dependent pathway. Autophagy 2011, 7:315-320.

39. Ferry JG: CO dehydrogenase. Annu Rev Microbiol 1995, 49:305-333.

40. Santiago B, Schubel U, Egelseer C, Meyer O: Sequence analysis, characterization and CO-specific transcription of the cox gene cluster on the megaplasmid pHCG3 of Oligotropha carboxidovorans. Gene 1999 236:115-124.

41. Kraut M, Hugendieck I, Herwig S, Meyer O: Homology and distribution of $\mathrm{CO}$ dehydrogenase structural genes in carboxydotrophic bacteria. Arch Microbiol 1989, 152:335-341.

42. Ragsdale SW: Life with carbon monoxide. Crit Rev Biochem Mol Biol 2004, 39:165-195.

43. Techtmann SM, Lebedinsky AV, Colman AS, Sokolova TG, Woyke T, Goodwin L, Robb FT: Evidence for horizontal gene transfer of anaerobic carbon monoxide dehydrogenases. Front Microbiol 2012, 3:132.

44. Ragsdale SW, Pierce E: Acetogenesis and the Wood-Ljungdahl pathway of CO(2) fixation. Biochim Biophys Acta 2008, 1784:1873-1898.

45. Ragsdale SW: Enzymology of the wood-Ljungdahl pathway of acetogenesis. Ann N Y Acad Sci 2008, 1125:129-136.

46. King GM: Molecular and culture-based analyses of aerobic carbon monoxide oxidizer diversity. Appl Environ Microbiol 2003, 69:7257-7265.

47. King GM: Uptake of carbon monoxide and hydrogen at environmentally relevant concentrations by mycobacteria. Appl Environ Microbiol 2003, 69:7266-7272

48. Park SW, Hwang EH, Park H, Kim JA, Heo J, Lee KH, Song T, Kim E, Ro YT, Kim SW, Kim YM: Growth of mycobacteria on carbon monoxide and methanol. J Bacteriol 2003, 185:142-147.

49. Park SW, Song T, Kim SY, Kim E, Oh Jl, Eom CY, Kim YM: Carbon monoxide dehydrogenase in mycobacteria possesses a nitric oxide dehydrogenase activity. Biochem Biophys Res Commun 2007, 362:449-453.

50. Roberts GP, Youn H, Kerby RL: CO-Sensing Mechanisms. Microbio/ Mol Biol Rev 2004, 68:453-473. table of contents.

51. Ryter SW, Otterbein LE: Carbon monoxide in biology and medicine. BioEssays 2004, 26:270-280.

52. Ascenzi P, Bocedi A, Leoni L, Visca P, Zennaro E, Milani M, Bolognesi M: CO sniffing through heme-based sensor proteins. IUBMB Life 2004, 56:309-315. 
53. Dioum EM, Rutter J, Tuckerman JR, Gonzalez G, Gilles-Gonzalez MA, McKnight SL: NPAS2: a gas-responsive transcription factor. Science 2002, 298:2385-2387.

54. Aono S, Honma Y, Ohkubo K, Tawara T, Kamiya T, Nakajima H: CO sensing and regulation of gene expression by the transcriptional activator CooA. J Inorg Biochem 2000, 82:51-56.

55. Aono S, Takasaki H, Unno H, Kamiya T, Nakajima H: Recognition of target DNA and transcription activation by the CO-sensing transcriptional activator CooA. Biochem Biophys Res Commun 1999, 261:270-275.

56. Roberts GP, Thorsteinsson MV, Kerby RL, Lanzilotta WN, Poulos T: CooA: a heme-containing regulatory protein that serves as a specific sensor of both carbon monoxide and redox state. Prog Nucleic Acid Res Mol Biol 2001, 67:35-63.

57. Youn H, Kerby RL, Conrad M, Roberts GP: Functionally critical elements of CooA-related CO sensors. J Bacteriol 2004, 186:1320-1329.

58. Shelver D, Kerby RL, He Y, Roberts GP: CooA, a CO-sensing transcription factor from Rhodospirillum rubrum, is a CO-binding heme protein. Proc Natl Acad Sci U S A 1997, 94:11216-11220.

59. Aono S: Biochemical and biophysical properties of the CO-sensing transcriptional activator CooA. Acc Chem Res 2003, 36:825-831.

60. Sardiwal S, Kendall SL, Movahedzadeh F, Rison SC, Stoker NG, Djordjevic S: A GAF domain in the hypoxia/NO-inducible Mycobacterium tuberculosis DosS protein binds haem. J Mol Biol 2005, 353:929-936.

61. Cairns J, Denhardt DT: Effect of cyanide and carbon monoxide on the replication of bacterial DNA in vivo. J Mol Biol 1968, 36:335-342.

62. Weigel PH, Englund PT: Inhibition of DNA replication in Escherichia coli by cyanide and carbon monoxide. J Biol Chem 1975, 250:8536-8542.

63. Lighthart B: Survival of airborne bacteria in a high urban concentration of carbon monoxide. Appl Microbiol 1973, 25:86-91.

64. Motterlini R, Clark JE, Foresti R, Sarathchandra P, Mann BE, Green CJ: Carbon monoxide-releasing molecules: characterization of biochemical and vascular activities. Circ Res 2002, 90:E17-24.

65. Tavares AF, Teixeira M, Romao CC, Seixas JD, Nobre LS, Saraiva LM Reactive oxygen species mediate bactericidal killing elicited by carbon monoxide-releasing molecules. J Biol Chem 2011, 286:26708-26717.

66. Nobre LS, Seixas JD, Romao CC, Saraiva LM: Antimicrobial action of carbon monoxide-releasing compounds. Antimicrob Agents Chemother 2007, 51:4303-4307.

doi:10.1186/2045-9912-2-30

Cite this article as: Zacharia and Shiloh: Effect of carbon monoxide on

Mycobacterium tuberculosis pathogenesis. Medical Gas Research 2012 2:30.

\section{Submit your next manuscript to BioMed Central and take full advantage of:}

- Convenient online submission

- Thorough peer review

- No space constraints or color figure charges

- Immediate publication on acceptance

- Inclusion in PubMed, CAS, Scopus and Google Scholar

- Research which is freely available for redistribution 